\title{
PRÁTICA DOCENTE NO ENSINO DE ADMINISTRAÇÃO: ANALISANDO A MEDIAÇÃO DA EMOÇÃO
}

\author{
Teaching practices in higher education management courses: \\ analyzing the mediation of emotion
}

\author{
Liliane Canopf* \\ Jucélia Appio** \\ Yára Lúcia Mazziotti Bulgacov*** \\ Denise de Camargo****
}

\section{RESUMO}

Considerando a emoção imprescindível na constituição do psiquismo e como mediadora inseparável da ação/cognição, acredita-se que ela é uma das condições essenciais no processo significativo de ensino-aprendizagem, que contribua na superação da razão instrumental dominante nos cursos de administração rumo a uma prática docente mais sensível. Com uma abordagem qualitativa, de caráter construtivo-interpretativo, a unidade de análise foi a prática docente de um curso de Administração de uma universidade federal brasileira. A prática, calcada no cotidiano, onde o singular é legítimo para produção de conhecimento científico (REY, 2005), foi concebida a partir da abordagem histórico-cultural. A pesquisa sustentou-se em um processo dialógico, com aplicação do método da autoconfrontação simples, com entrevistas e notas de campo. Os resultados apoiaram a tese da emoção como mola propulsora do processo significativo de ensino-aprendizagem, sustentada pelo pressuposto teórico de que a emoção é a "gênese e sustentação da atividade humana e construtora de sentido" (CAMARGO, 2012, p. 1).

Palavras-chave: Emoção. Prática docente. Ensino de administração.

\begin{abstract}
Considering emotion to be indispensable in the constitution of the psyche and as an inseparable mediator of action/cognition and of a meaningful teaching-learning process, emotion is hypothetically considered as one of the essential conditions for overcoming purely instrumental reason, which is dominant in Management undergraduate programs, and for nourishing a more sensible reason that incites critical and reflective attitudes, as well as a more plural way of facing reality. By means of a qualitative approach, of a constructive-interpretative nature, the importance of the mediation of emotion in the teaching-learning process was investigated. The unit of analysis consisted of the teaching practice in a Management undergraduate course in a Brazilian federal university. The practice, based on daily activities, where an individual's singularity is legitimate for building up scientific knowledge (REY, 2005), was conceived through the cultural-historical approach. The research was based on a dialogic process, with the employment of simple self-confrontation method, interviews and field notes. The results support the proposition that emotion as a propeller of a meaningful process of teaching and learning, underpinned by the theoretical presupposition that emotion is the "genesis and support of human activity and construction of meaning (CAMARGO, 2012, p. 1).
\end{abstract}

Keywords: Emotion. Teaching practice. Teaching of administration.

\footnotetext{
* Professora do Programa de Pós-graduação em Administração da Universidade Federal Tecnológica do Paraná - UTFPR. Doutora em Administração pela Universidade Positivo (PMDA/UP). E-mail: lilianec@utfpr.edu.br

** Professora do Curso de Administração da Universidade Estadual do Oeste Paranense (Unioeste/PR). Doutora em Administração pela Universidade Positivo (PMDA/UP). E-mail: juceliaappio@yahoo.com.br

*** Professora Titular do Programa de Mestrado e Doutorado em Administração da Universidade Positivo (PMDA/ UP) e professora Sênior da Universidade Federal do Paraná (UFPR). Doutora em Educação pela Universidade Estadual de São Paulo (UNESP). E-mail: ybulgacov@gmail.com

**** Professora Titular do Programa de Mestrado e Doutorado em Psicologia da Universidade Tuiuti do Paraná (PPG/UTP) e professora Sênior da Universidade Federal do Paraná (UFPR). Doutora em Psicologia pela Pontifícia Universidade Católica de São Paulo (PUC/SP). E-mail: denicamargo@gmail.com.
} 


\section{INTRODUÇÃO}

$\mathrm{O}$ s cursos de administração têm sido alvo de muitas críticas (CANOPF, 2013; DAVEL et al. , 2004; CHANLAT, 1996; GUERREIRO RAMOS, 1981). Guerreiro Ramos (1981) denunciou o impacto desfigurador sobre a vida humana associada à organização pela dominância da racionalidade instrumental e pré-reflexiva, baseada no cálculo utilitário de consequências e voltada apenas ao êxito econômico, que representava para ele uma clara redução da realidade humana. Por isso, propôs em sua nova ciência das organizações uma teoria substantiva na qual os conhecimentos são derivados no e do processo da realidade humana. Reforçando esta crítica, Chanlat (1996) aponta o ensino e a formação do administrador como tendo alto grau de especialização, rigidez, anti-intelectualismo, etnocentrismo, quantitativismo, economismo, incultura, ausência de consciência histórica, inaptidão para comunicar e interagir. Para Valadão (2011) o fazer científico na administração, ao perseguir a objetividade, deixa implícito temas ligados à necessidade de melhor conhecer a relação professor-aluno que contribuiriam para promover mudanças qualitativas e atenderiam às demandas contemporâneas. 0 autor acredita ainda que este fazer científico não contribui para que o administrador adquira uma atitude crítica e reflexiva, com valorização do contexto da prática administrativa e uma visão mais plural da realidade.

Corroborando com estes autores, Davel et al. (2004) apontam que o ensino de administração se afasta da vida cotidiana, com pouca relevância prática e incitação ao desenvolvimento de habilidades gerenciais capazes de lidar com problemas complexos, reais e aspectos cotidianos mais afetivos, estéticos, intuitivos e evocativos das organizações, da administração e do trabalho. Acredita-se que um caminho possível para se afastar das tradições fundadas na objetividade, na racionalidade e em perspectivas externalistas/mecanicistas é, como destaca Rey (2003), expor o caráter real de fenômenos não tangíveis, mas próprios da condição humana. Assim, volta-se para o mundo dos afetos, que para Vigotski ${ }^{1}$ (2010) é um mundo real que interage de forma contínua e forte sobre a vida dos indivíduos.

A escola foi escolhida como locus de pesquisa, pois é o espaço em que os atores sociais que nela atuam devem expor, construir e reconstruir seus sentimentos e emoções como função integradora do processo de ensino-aprendizagem. Para Kastrup (1999) a emoção responde, inclusive, pelo movimento divergente do pensamento, sendo criadora enquanto força o sujeito a sair do lugar-comum. Sendo assim, defende-se a tese de que a emoção contribui para a formação de um pensamento complexo e não linear, que possibilita a formação de um administrador mais substantivo.

A escolha do curso de administração para a pesquisa foi um desafio motivado pela significativa inserção do curso de administração no ensino superior no Brasil e no mundo. Segundo dados do Instituto Nacional de Estudos e Pesquisas Educacionais Anísio Teixeira - INEP (2014), o curso de administração em 2013 contou com 800 mil matrículas, tendo

1. Conforme Teixeira (2005), Romanelli (2011) e Canopf (2013), há na literatura diferentes transliterações para o sobrenome do autor, tais como: Wygotsky, Vygotsky, Vygotskj, Vygotski, Vigotskii, Vigotski. Segundo os autores, há dois motivos para tal, quais sejam (i) o som de algumas letras do alfabeto cirílico nem sempre têm equivalentes em caracteres do nosso alfabeto; e (ii) existem particularidades das diferentes línguas ocidentais para as quais se traduzem as obras do autor. Neste trabalho, o nome será grafado com "i". Contudo, mantém-se a grafia original nas citações diretas de outros autores, bem como nas referências bibliográficas. 
o maior número de formandos em ensino superior no Brasil, sem considerar os diversos estudantes vinculados a cursos de pós-graduação lato e sctricto sensu.

O aumento dos cursos de administração torna maior o desafio de tornar a escolaridade significativa para o desenvolvimento intelectual dos alunos (SFORNI, 2003, p. 1), considerando que o desenvolvimento intelectual deve exceder a capacidade de reprodução de conhecimento, pressupondo mudanças qualitativas no desenvolvimento do pensamento bem como uma aprendizagem autônoma e significativa. Esse ideal não tem sido alcançado em decorrência da priorização dos aspectos intelectuais e cognitivos, por meio de atividades reprodutoras, vinculadas à memória e à reprodução de normas de conduta já elaboradas, que impedem a expressão e organização das emoções. A organização da escola, ao deixar de oferecer espaço para as atividades criadoras, dificulta a expressão da integridade, da totalidade do aluno como indivíduo (CAMARGO, 2004).

Assim, é olhando para a necessidade de repensar a formação do administrador, na busca de condições que favoreçam a adoção de uma atitude crítica, reflexiva e sensível, com valorização do contexto da prática, que desperte nos alunos uma visão mais plural e não dicotômica da realidade (LOURENÇO et al., 2009) que esta pesquisa propõe, segundo os pressupostos da abordagem histórico-cultural (VIGOTSKY, 1998), analisar a mediação da emoção na prática docente de um curso de administração.

A adoção do conceito de prática docente é ao mesmo tempo uma perspectiva empírica bem como teórica. Prática docente nesta pesquisa foi concebida como sistemas de atividade humana que se inter-relacionam tendo como fundamento a Teoria da Atividade proveniente da Psicologia Histórico-cultural russa. Uma psicologia que abandona a visão abstrata e racionalista adotando uma concepção de homem concreto cuja subjetividade é constituída e constituinte do próprio contexto histórico, social e cultural.

Até a realização desta pesquisa não haviam trabalhos nas bases de dados de pesquisas brasileiras com o tema emoção vinculado à prática docente voltada à formação do administrador. Nas bases de dados internacionais disponíveis na internet, com categorias de busca Management, Graduate, Education e Teacher, os artigos encontrados foram estudos comparativos dos modelos de ensino norte-americano com o de outros países. Ao acrescentar-se a categoria Emotion, os trabalhos encontrados eram nas áreas de psicologia e educação, estudos sobre ensino para crianças e adolescentes e pesquisas que tratavam quantitativamente da administração da emoção de funcionários no contexto de organizações empresariais.

Focou-se a emoção porque acredita-se que ela contribui para que o aprender extrapole o reter informações (CAMARGO, 2004). Como afirma Vigotski (2010), a emoção não é um agente menor do que o pensamento, ao contrário, são precisamente as reações emocionais que devem constituir a base do processo educativo. 0 professor deve preocupar-se em ligar emoção a um novo conhecimento, seu trabalho deve consistir não só em fazer com que os alunos pensem e assimilem um novo conteúdo, mas que também o sintam. "Todo o resto é saber morto, que extermina qualquer relação viva com o mundo." (VIGOTSKI, 2010, p. 144).

Considerado os aspectos acima mencionados, o presente trabalho, a partir de uma perspectiva qualitativa de pesquisa e dando voz a professores e alunos de um curso de 
Administração de uma universidade federal brasileira, pretende dar sustentação empírica ao argumento de que a emoção é a mola propulsora do processo de ensino-aprendizagem, geradora e sustentadora de qualquer atividade humana e construtora de sentido (CAMARGO, 2012). Para tanto, este texto está dividido em quatro seções. A primeira é a introdução do tema, a segunda seção compreende o desenvolvimento teórico, a terceira a metodologia, e, finalmente, as considerações finais desta pesquisa.

\section{REFERENCIAL TEÓRICO}

Este tópico contém três seções que fornecem os pressupostos teóricos assumidos nesta pesquisa. No primeiro apresentam-se os fundamentos da Teoria da Atividade, o segundo subsidia a compreensão de prática docente seguido pela fundamentação da emoção na mesma.

\subsection{FUNDAMENTOS HISTÓRICO-CULTURAIS DA TEORIA DA ATIVIDADE}

Para realizar a análise situada da emoção como mediadora na prática docente, o principal suporte foi a Teoria da Atividade. A prática docente foi conceituada como um conjunto de sistemas de atividade humana, cotidianas, concretas, neste acaso ocorridas no espaço da sala de aula, comportando professores e alunos. Especificamente: sistema de atividade de aula expositiva; sistema de atividade de aplicação de teoria em situações concretas; e sistema de atividade de verificação de apropriação de conceitos teóricos por parte dos alunos. São sistemas de atividades que compõem a prática docente e estabelecem a relação entre professores e alunos, além de comporem o processo ensino-aprendizagem.

A Psicologia Histórico-cultural, base da Teoria da Atividade, toma a atividade humana como categoria central e compreende o homem como atuante no mundo, e cuja ação transforma a si e ao mundo. A concepção dialética de atividade considera o homem como produto e produtor de um processo de desenvolvimento profundamente enraizado nas ligações entre história individual e história social e que a consciência do indivíduo procede da relação dialética deste com a experiência (TEIXEIRA, 2005). Esta é a proposta desta pesquisa, olhar a atividade humana cotidiana, e como esta se desenvolve a partir das peculiaridades de uma dada situação.

Para Vigotski (1998; 2010), base da Teoria da Atividade, o conceito de mediação é fundamental. 0 homem não tem um relacionamento direto com o ambiente, esta relação é mediada pela atividade do homem no mundo e por artefatos (instrumentos físicos e simbólicos), construindo uma atividade geradora da consciência e significativa no mundo. Assim, ele expressava que não só a consciência, mas as funções psicológicas superiores se originam da atividade sociocultural humana. 0 homem é compreendido então como um ser histórico-cultural que se constitui por sua atividade no mundo. Seus estudos voltaram-se para o entendimento do desenvolvimento individual, focando na análise das mudanças que se produziam nas funções psicológicas superiores como consequência das atividades mediadas por instrumentos físicos e sobretudo símbolos, pela linguagem, essencialmente 0 que diferenciava o homem dos animais. 
Contudo, a Teoria da Atividade não é exclusiva da abordagem teórica de Vigotski. Ele é compreendido como o teórico da primeira geração. A segunda geração da teoria da atividade é representada por um de seus discípulos, Leontiev. Mais recentemente, a terceira geração é representada por Yrjo Engeström.

Vigotski (1998), por um lado, preocupava-se com o desenvolvimento humano individual mediado pela cultura, por outro, Leontiev (2004) introduziu um modelo de análise da atividade mediada pela experiência coletiva e pela divisão de trabalho. Se, por um lado, Vigotski (1998) olha para o indivíduo e seu desenvolvimento pela atividade, por outro, Leontiev (2004) contribui trazendo o conceito do coletivo e da mediação do coletivo na atividade humana.

Finalmente e mais recentemente instaura-se a terceira geração representada por Engeström (1987) propondo uma reconceitualização da Teoria da Atividade. Ele propõe um conceito de atividade mediado pela experiência coletiva e pela divisão de trabalho que amplia a noção de atividade propondo a interseção de sistemas de atividade e suas transformações. $\mathrm{O}$ autor defende $\mathrm{o}$ estudo de ferramentas ou artefatos como componentes integrais e inseparáveis do funcionamento humano e sustenta que o foco do estudo da mediação deve ser na sua relação com os outros componentes de um sistema de atividade. Amplia os elementos sociais/coletivos do sistema de atividade e propõe, além da divisão de trabalho, os elementos comunidade e regras, com ênfase na análise das interações recíprocas entre sistemas de atividades.

Este estudo concebe estas três abordagens como complementares proporcionando uma base teórica mais completa para a compreensão da prática docente. A atividade do professor é uma atividade voltada tanto para o desenvolvimento dos alunos, mas também de si mesmo, uma relação que não é individual, é coletiva e formada por vários sistemas de atividades que interagem entre si e sobretudo, mediada pela emoção em sua função dinamogênica.

Nestas perspectivas, a prática passa a ser vista como uma atividade essencialmente humana e criadora de sentido, que pode ser entendida como uma atividade dirigida, situada e estudada a partir do cotidiano, da rotina diária, da vida realmente vivida no mundo, da forma pela qual os corpos são movimentados, os objetos são manipulados, os sujeitos interagem, de como as coisas são descritas e o mundo é compreendido (CASSANDRE et al., 2010).

Em síntese, a prática docente, neste estudo, é entendida como sistemas de atividades docentes e, entende-se que atividades humanas são mediadas e situadas socialmente. É na relação do indivíduo com o meio que emerge a prática social como principal força que dirige a evolução do pensamento. Pode-se dizer que a prática humana é a própria base do conhecimento humano (TEIXEIRA, 2005), mas não é uma relação de determinação externa, é uma relação recursiva em que cada um está simultaneamente implicado na configuração plurideterminada dentro da qual se manifesta a ação do outro, gerando um sujeito de caráter dialético e complexo, um homem concreto que, de forma simultânea, representa uma singularidade e um ser social (REY, 2003). Convém destacar que a mediação da emoção nesse processo dialético é uma das responsáveis pela singularidade, ambivalências, e estilos particulares (BRETON, 2009). 
A Teoria da Atividade contribuiu com categorias de análise na construção de uma abordagem de prática social como uma prática historicamente constituída e reconstituída pela ação humana e social, ou seja, uma prática reflexiva. Frente a essas características, Norman (1993 apud DANIELS, 2011) passou a tratar da atividade como situada. Não se pode olhar apenas para a situação, ou apenas para o ambiente, ou apenas para a pessoa, ou apenas para o seu fazer. Considerar estes desta forma é destruir o próprio fenômeno de interesse, é destruir a interação eliminando o papel da situação sobre a cognição e sobre a ação. É a mútua acomodação das pessoas, seu fazer, seu ambiente que interessa. Como Lave e Wenger (1991 apud DANIELS, 2011, p. 131) observaram: "situado [...] sugere que uma dada prática social é multiplicar interconectado com outros aspectos de processos sociais contínuos em sistemas de atividade em muitos níveis de particularidade e generalidade." A atividade passa a ser endereçada e dirigida, simultaneamente, para seu objeto e para as outras atividades que incidem sobre esse objeto, sejam elas do outro ou de outras atividades do sujeito (CLOT, 2010). O objeto de estudo histórico-cultural são eventos, atividade e prática, "sendo metodologicamente necessário estudar práticas situadas" (DANIELS, 2011, p. 123).

\subsection{A ATIVIDADE E A PRÁTICA DOCENTE}

Libâneo (2004) considera que a Teoria da Atividade contribui para compreender a prática docente, pois a partir dela surge a possibilidade de tratar temas como a atividade humana e a prática de aprendizagem, enquanto atividade situada em contextos históricos e culturais. Segundo Davydov (1988 apud LIBÂNEO, 2004), a atividade humana concreta é constituída por desejos, necessidades, emoções, tarefas, ações, motivos e meios usados para as ações e planos, elementos que estruturam a atividade e que se referem à cognição e também à vontade. Para ele, a atividade de aprendizagem tem como premissa a possibilidade de formar em uma pessoa certas capacidades ou qualidades mentais por meio do ensino e da educação. São as práticas de aprendizagem como articulação entre processos internos e externos que visam à apropriação de signos culturais e à geração de uma qualidade autorreguladora das ações e do comportamento dos indivíduos. A educação é a forma dominante pela qual se propiciam mudanças qualitativas no desenvolvimento do pensamento, com destaque para a mediação docente que se põe entre o aluno e o conhecimento, para possibilitar as condições e os meios de aprendizagem, ou seja, mediações cognitivas (LIBÂNEO, 2004).

Camargo (2004) não somente defende aprendizagem como atividade, mas a entende como atividade coletiva e situada. Para ela, aprendizagem é sobretudo atividade criadora e não apenas atividade reprodutora. Para a aprendizagem, enquanto atividade criadora, é essencial a mediação da afetividade, rompendo com a concepção de aprendizagem enquanto cognição fria.

Para Garnier, Bednarz e Ulanovskaya (1996), a atividade permite introduzir as bases necessárias ao desenvolvimento psicológico, pois é através da atividade concreta que o conhecimento é adquirido e que as regras que comandam este processo de aquisição são estabelecidas. As significações e as interações sociais têm papel determinante na construção do conhecimento, a aprendizagem efetua-se no interior dos processos grupais, 
como resultado da interação de processos interindividuais e intraindividuais, no centro de uma rede de comunicações múltiplas, que se desenvolvem dentro de um contexto no qual o professor concebe situações que otimizam essas interações e oportunizam desenvolvimento.

Segundo estas autoras, a elaboração do conhecimento pelo aluno encontra-se na intersecção de diversas formas de inter-relações sociais, das quais pode-se distinguir três: entre pares, entre alunos e professor, e entre o professor e a turma. A sala de aula é o espaço social no qual as interações de todos os parceiros estão focalizadas sobre saberes de origem cultural, lugar de confrontações que conduzem, eventualmente, a conflitos sociocognitivos, nos quais pode-se superar as concepções iniciais, evoluindo em conhecimentos e procedimentos. É a análise e o planejamento das ações para a resolução de problemas que gerarão a reflexão teórica dos alunos. Por isso a importância da elaboração de situações pedagógicas como um processo que combina a análise da ciência e a análise das ações, em suas duas dimensões sociais: enquanto resultado da cultura e como processo interativo no decorrer do qual se realiza a apropriação da mesma. 0 professor é o representante de um projeto social educacional que satisfaz a demandas sociais e culturais e os alunos devem estar implicados no aprendizado, enquanto sujeitos sociais, para que as situações de classe repousem sobre interações entre parceiros (GARNIER; BEDNARZ; ULANOVSKAYA, 1996).

Para Vigotski (1998) a escola tem um papel fundamental no desenvolvimento humano. No processo educacional a cooperação sistemática entre professor e aluno dá ao aluno as condições necessárias ao desenvolvimento do conceito científico. Breton (2009) afirma que o homem não existe sem a educação, que modela relação dele com o mundo e com os outros e seu acesso à linguagem.

Ao criar e organizar um ambiente e situações capazes de provocar aprendizado, o professor deve engajar-se de forma decisiva (GARNIER; BEDNARZ; ULANOVSKAYA, 1996). No entanto, aprendizagem, enquanto um processo de virtualização da ação, não é o que promovem escolas que impedem o exercício do pensamento produtivo, com práticas que privilegiam o automatismo mental. Pensamento produtivo é o único pensamento que pode ser reconhecido como aprendizagem, distinguindo-se das condutas reprodutivas e dos tateamentos mecânicos (DANIELS, 2011). É preciso estabelecer as condições para uma aprendizagem inteligente e sensível (PENNA, 1978 apud KASTRUP, 1999).

\subsection{A EMOÇÃO E A PRÁTICA DOCENTE}

Esta seção pretende subsidiar teoricamente a tese de que a emoção está presente na prática docente e influencia a aprendizagem. Na medida em que conceituamos práticas de aprendizagem como conjunto de atividades educativas faremos uma digressão para refletir a postura de Vigostki em relação a mediação da emoção na atividade humana e a mediação da emoção no conjunto das atividades educativas.

Neste momento apresenta-se uma breve revisão dos posicionamentos teóricos de Vigotski $(1998 ; 2010)$ e de alguns de seus comentadores, tais como, Clot (2007), Camargo (2004; 2012), Camargo e Bulgacov (2006) e Bulgacov e Vizeu (2011). Na mesma perspectiva, são apresentados teóricos relevantes para o tema emoção na atividade bem como na prática docente como Maffesoli (2005), Barrett (2012), Goleman (1995) e Breton (2009). 
Uma das questões centrais que caracteriza a contribuição de Vigotski é afirmar que o homem se torna humano. Para ele, é a aprendizagem no mundo e o desenvolvimento humano os responsáveis pela constituição do homem. É a atividade, o agir do homem no mundo, que desenvolve as funções psicológicas superiores.

Camargo (2004) conceitua a função primária da emoção no desenvolvimento do indivíduo. Para ela, a emoção precisa ser compreendida no bojo de um sistema motivacional maior, que pode ser definido como uma ação de um sistema orgânico total, com componentes de representação, expressão e motor-fisiológico, diferente do termo sentimento, que pode ser empregado à uma expressão motor-fisiológica menos declarada do que em emoção. Assim, a emoção tem uma função primária no indivíduo e se torna complexa no decorrer do processo de apropriação da cultura, estabelecendo relações com outras funções psicológicas como atenção, memória, percepção, pensamento e vontade, formando um sistema motivacional complexo e interdependente, mediado pela relação com os outros e pela linguagem.

Para Heller (1993), aprende-se a sentir e as emoções são os sentimentos mais complexos aprendidos. As emoções não são estados absolutos, substâncias que podem ser transpostas de um indivíduo ou grupo a outro. Tampouco são, ao menos exclusivamente, processos fisiológicos cujos segredos estariam contidos no corpo, tratam-se de relações.

Em outras palavras, a emoção está presente na atividade e, a partir de sua expressão fisiológica, é construída social e culturalmente. Afirmar a construção social da emoção significa não buscar a generalização do seu papel, relevância ou implicação, mas propor uma análise situada em uma determinada prática, no presente caso a docente, em um dado espaço sócio, histórico e cultural, um curso de Administração. A prática docente é entendida como uma prática cultural, enraizada no social e singular, o que denota sua complexidade constituída em um dado lugar, enraizado no social e no cultural e, portanto, singular. Um particular que representa os processos humanos de constituição social da emoção.

No pensamento de Vigotski (2010, p. 146), "o aspecto emocional do indivíduo não tem menos importância do que outros aspectos e é objeto de preocupação da educação nas mesmas proporções em que o são a inteligência e a vontade", acreditando que momento da emoção e do interesse deve, necessariamente, servir de ponto de partida a qualquer trabalho educativo. As emoções abrem um meio rico para a educação, pois nenhuma forma de comportamento é tão forte quanto aquela ligada a uma emoção. A experiência e estudos de Vigotski, mostraram que o fato emocionalmente colorido é lembrado com mais intensidade e solidez do que um fato indiferente. "Sempre que comunicamos alguma coisa a algum aluno devemos procurar atingir o seu sentimento. Isso se faz necessário não só como meio para melhor memorização e apreensão, mas também como objetivo em si." (VIGOTSKI, 2010, p. 143).

$\mathrm{Na}$ tentativa de transpor estas premissas para o campo da administração, confrontando a racionalidade, a cognição "fria", lembra-se que Vigotski associa a emoção à intencionalidade. Ele não substitui a racionalidade pela emoção. Não dicotomiza razão e emoção. Para Vigotski (2010), a emoção está vinculada ao propósito, é o propósito que irá decidir o jogo e justificar a atividade e, como objetivo final, determinar a atitude afetiva, dando espaço a possibilidades de desenvolvimento. O sentimento não surge por si só, é sempre antecedido por estímulo e sua causa pode ser externa ou interna. "Toda emoção é um chamamento à ação ou uma renúncia a ela." (VIGOTSKI, 2010, p. 139). 
Esclarece Camargo (2004) que, para Vigostki, o homem é um agente intencional, pois apenas ele entre todos os seres vivos desenvolve a habilidade de compreender a intencionalidade do outro. Segunda a autora, Vigostki foca nas transformações que a emoção sofre ao longo desenvolvimento dos indivíduos. De função primária ela se torna complexa no decorrer do processo de apropriação da cultura e passa a estabelecer relações interfuncionais com as outras funções psicológicas, formando um sistema complexo mediado pela linguagem. Vigotski (2010) aponta que o fato do racional e o emocional são partes um do outro, ambos localizados em nossas crenças, às vezes profundamente retidas e amiúde largamente tácitas acerca do mundo, da educação, da pesquisa e da escrita. Desse modo, a reação emocional é um processo organizador do comportamento, nela se realiza a natureza ativa do organismo.

O mundo dos afetos é um mundo real que interage de forma contínua e forte sobre a vida dos indivíduos, sejam eles alunos ou professores. A escola é o espaço em que os atores sociais que nela atuam devem expor, construir e reconstruir seus sentimentos e emoções como função integradora do processo de aprendizagem. Toda emoção pode ser orientada pelo educador em qualquer sentido e ligar-se a qualquer estímulo, tornando o trabalho educacional em uma fonte inesgotável de excitações emocionais (VIGOTSKI, 2010). Barrett (2012) condensa esse pensamento na declaração de que as emoções são parte da realidade social, são, ao mesmo tempo, socialmente construídas e biologicamente evidentes.

Clot (2007, p. 32), fundamentado em Vigotski, afirma que é na mediação da emoção, no seu papel dinamogênico no comportamento humano, que se forma a ação mental, "comover é pôr em movimento", é tonificar o corpo para agir. Em uma atividade, com o tempo necessário disponibilizado, as emoções se convertem em um instrumento de ação eficaz, constituindo o fenômeno fundamental da natureza humana.

Assim, o homem é afetado pelo mundo em todo seu ser, inclusive em suas emoções (BULGACOV; VIZEU, 2011). "Ora, a vida empírica está aí para mostrar que, ao lado da razão, a paixão ou a emoção ocupam lugar inegável; pode-se até dizer, um lugar cada vez mais importante." (MAFFESOLI, 2005, p. 165).

Goleman (1995) reforça o caráter não dicotômico da razão e da emoção sinalizando seu fim produtivo, sua habilidade mestra seja no controle de impulsos ou no adiamento da satisfação, bem como no controle de estados de espírito para que facilitam, em vez de impedir o pensamento, motivando a persistência, a descoberta e a eficiência, indicando o poder da emoção na orientação do esforço eficaz. Nesta mesma linha de pensamento, Bulgacov e Vizeu (2011) sinalizam, mesmo que em relação à prática da pesquisa, mas extensivo a atividade humana em geral, a positividade da emoção.

Breton (2009) nos traz importantes reflexões em relação à emoção. A emoção, declara o autor, tem ligação com acontecimentos passados, presentes e futuros, reais ou imaginários na relação do indivíduo com o mundo. Acentua seu caráter breve, fugaz e ao mesmo tempo explícito em termos gestuais, mímicas, posturas e modificações fisiológicas. Destaca a relação da emoção com o acontecimento moral, social e culturalmente marcados que exercem influência nos recursos interpretativos e na sensibilidade individual. Para ele, as emoções não são espontâneas, mas ritualmente organizadas, reconhecidas em si e exibidas aos outros, mobilizam um vocabulário e discursos, pois provêm da comunicação social. O indivíduo aplica suas peculiaridades sobre um tecido coletivo reconhecível por seus pares, 
ele as desenha de acordo com sua história pessoal, sua psicologia, seu status social, seu sexo, sua idade, entre outras características individuais. As emoções nutridas pelos indivíduos distribuem os valores e as hierarquias que sustentam a afetividade (BRETON, 2009).

$\mathrm{Na}$ aproximação da emoção com a prática docente alguns autores, como os expostos abaixo, clarificam e reforçam esta relação. Para Heller (1993), um ato de inteligência - cognição, solução de problemas - não pode existir sem implicação, por isso aprendizagem e sentimento avançam conjuntamente. Enfatiza a autora sua posição contrária à uma cognição "fria", postura de quem dicotomiza emoção/razão.

Kastrup (1999) é outra autora partidária da junção razão/emoção, a qual adiciona o caráter criador como gerador de pensamento e invenção, ainda que de ordem intelectual. Acredita que a emoção é a base para um pensamento divergente, aspecto fundamental para uma educação crítica, criativa e sensível. Assim, a prática docente é uma atividade implicada em que o vínculo afetivo é necessário para a aprendizagem e que a aprendizagem pode propiciar um vínculo afetivo positivo.

Esse ideal não tem sido alcançado em decorrência da priorização dos aspectos intelectuais e cognitivos, por meio de atividades reprodutoras, vinculadas à memória e à reprodução de normas de conduta já elaboradas, que impedem a expressão e organização das emoções. A organização da escola, ao deixar de oferecer espaço para as atividades criadoras, dificulta a expressão da integridade, da totalidade do aluno como indivíduo (CAMARGO, 2004). Em oposição a essa forma de atividade, a autora propõe as atividades criadoras, que compreendam a reelaboração e criação de novas ações, imagens, normas e planos, a partir de elementos das experiências passadas dos alunos. É tomar o caminho da criatividade nas atividades pedagógicas, uma vez que o processo criativo necessita do amálgama das emoções.

O que determina a importância de uma emoção é a potência de criação dela. Assim, não é qualquer emoção que importa, mas aquelas que persistem no sujeito, apresentando-Ihe um problema e exigindo solução. Em estudo sobre a evasão e o abandono escolar no ensino fundamental, Camargo (2004) verificou que os alunos que revelam as emoções mais negativas com relação aos seus vínculos afetivos com professores, colegas e a própria família, são os que apresentam um histórico escolar repleto de reprovações, caminho comum para a exclusão.

A desatenção para o aspecto emocional na aprendizagem tem como efeito negar o próprio aluno como sujeito em desenvolvimento, com particularidades únicas e intensamente exposto aos fatores sociais, culturais e afetivos, afinal, aprendizado é corporificação, é emocional, social, cultural e parcialmente tácito (BOURDIEU; WACQUANT, 1992 apud KASTRUP, 1999). Como diz Kastrup (1999) é necessário que a cognição seja inquietada por algo que a force a inventar. É o que reforça Vigotski, que a educação é parte da vida cotidiana e repousa sobre múltiplas experiências de forte carga emocional, podendo ser a emoção seu elemento inquietador por excelência.

A partir desses pressupostos, espera-se revelar a "emoção enquanto gênese e sustentação da atividade humana e construtora de sentido" (CAMARGO, 2012, p. 1) e uma prática docente componente de um processo significativo de ensino-aprendizagem. 


\section{METODOLOGIA}

A presente pesquisa foi configurada a partir do referencial teórico-metodológico da Teoria da Atividade. A prática docente foi conceituada enquanto sistemas de atividades inter-relacionadas como aponta a concepção de atividade de Engeström (1987). Foram considerados três sistemas de atividades inter-relacionadas e próprias do cotidiano de sala de aula, a saber: sistema de atividade de aula expositiva; sistema de atividade de aplicação da teoria em situações concretas; e sistema de atividade de verificação da apropriação de conceitos teóricos por parte dos alunos. Estes sistemas de atividades foram selecionados por sua importância no processo ensino-aprendizagem, bem como pela possibilidade de observação no contexto da sala de aula, que ocorreu pelo método da autoconfrontação simples que comporta filmagens, entrevistas semiestruturadas e anotações de campo.

A unidade de análise foi a prática docente no espaço social da sala de aula. A mediação da emoção na relação professor aluno que se dava a partir dos sistemas de atividade propostos foi o objeto de estudo. Ao se considerar o enraizamento social e cultural da prática docente não se buscava a generalização estatística, mas uma análise singular e situada em seu contexto. O caráter construtivo-interpretativo (REY, 2005; CLOT, 2007), é baseado no complexo tecido de fatos e ideias, que situa o conhecimento em um âmbito interpretativo. $A$ organização deste processo ocorre no curso da própria pesquisa e mediante os vários canais de informação que foram definidos e se articulam, podendo ser revistos, se for necessário.

O locus foi um curso de Administração de uma universidade federal brasileira, que contava com a atuação de 11 professores advindos de diversos departamentos da instituição e 87 alunos distribuídos em dois semestres. Os sujeitos da pesquisa foram seis professores que, após serem apresentados ao projeto de pesquisa em reunião com a coordenação de curso, demonstraram real interesse em participar da mesma. Todos os 87 alunos que estudavam no curso, após apresentação do projeto às turmas em sala de aula, aderiram à pesquisa.

A conversação é um processo ativo de comunicação em que o outro se envolve em suas reflexões e emoções (REY, 2005), gerando uma corresponsabilidade, pois cada um dos participantes se sente sujeito do processo, facilitando a expressão de suas necessidades, interesses, dúvidas, tensões, reflexões e emoções. Assim, participantes do curso se converteram em respondentes, implicando-se no problema pesquisado a partir de seus interesses, desejos e contradições.

A análise situada da prática se desenvolveu a partir da tensão permanente entre o momento empírico e a produção intelectual do pesquisador, gerando novas zonas de inteligibilidade da realidade. Zona de inteligibilidade é definida por Rey $(2005$, p. 7) como "aqueles espaços de inteligibilidade que se produzem na pesquisa científica e não esgotam a questão que significam, senão que pelo contrário, abrem a possibilidade de seguir aprofundando um campo de construção teórica". Tal conceito tem uma profunda significação epistemológica que confere valor ao conhecimento, não por sua correspondência linear e imediata com o "real", mas por sua capacidade de gerar campos de inteligibilidade que possibilitem o surgimento de novas zonas de ação sobre a realidade e novos caminhos de trânsito dentro dela através de representações teóricas. O conhecimento legitima-se na sua continuidade e na sua capacidade de gerar novas zonas de inteligibilidade acerca do que 
é estudado e de articular essas zonas em modelos cada vez mais úteis para a produção de novos conhecimentos.

As transcrições das entrevistas foram confrontadas umas com as outras e com a teoria. A significação de cada registro empírico foi um ato de produção teórica, o qual, em seu conjunto, está por trás desse ato de inteligibilidade (REY, 2005). Assim, os indicadores de emoção que emergiram da relação professor-aluno presentes no processo de ensino-aprendizagem no contexto dos sistemas de atividades propostos da prática docente, foram negociados com os pressupostos teóricos da Teoria da Atividade, gerando áreas de inteligibilidade. Conforme o referencial teórico adotado é pressuposto a mediação da emoção em todos os processos de interação e a consequente produção de sentido para os sujeitos, no entanto, ela é importante no processo de ensino-aprendizagem?

Considerando que a emoção se faz presente tanto na expressão corporal quanto na falada (VIGOTSKI, 2010) foram considerados indicadores a participação efetiva (significativa) dos sujeitos nas atividades bem como os gestos, posturas, mímicas simpatia e antipatia, gostar e não gostar, raiva, desgosto, medo, paixão, ciúme, prazer, desprazer, irritação, tom e altura da voz e deslocamentos dos sujeitos no espaço social da sala de aula. Os indicadores de emoções na expressão falada e corporal emergiram da observação, filmagens e entrevistas, na busca da apreensão da emoção nas relações no espaço da sala de aula.

Após a gravação, os vídeos foram apresentados aos participantes e funcionavam como estímulos a manifestações "espontâneas" que ajudavam nas descrições subjetivas dos participantes de suas emoções manifestas tanto pela linguagem corporal como pela fala. Técnica denominada por Clot (2007) de autoconfrontação. As observações dos participantes frente as filmagens, geraram notas de campo nas quais o pesquisador registrou reflexivamente interações mediadas pelas emoções. 0 registro das interações, conexões e relações é um aspecto importante na pesquisa da emoção (BULGACOV; VIZEU, 2011).

Tendo como fundamento a abordagem de pesquisa qualitativa de Clot (2007), ao confrontar os participantes com os vídeos das atividades, procurava-se levá-los a se interrogarem sobre o que eles observavam da própria atividade, convidando-os a descrever o mais precisamente o possível os gestos e as operações observáveis na gravação em vídeo até que "se manifestassem os limites dessa descrição, até que a verdade estabelecida fosse flagrada na veracidade do diálogo, pela autenticidade dialógica." (CLOT, 2007, p. 240).

Confrontaram-se também as falas dos professores com a interação e falas dos alunos, observadas em sala de aula e obtidas em entrevistas semiestruturadas. As entrevistas semiestruturadas, foram realizadas individualmente com os professores, após estes assistirem seus vídeos, e coletivamente em sala de aula com alunos. Ambas tinham um roteiro de perguntas abertas, eram gravadas e transcritas e posteriormente lidas para os participantes, que podiam fazer alterações no texto, aprofundamento ou esclarecimento de suas falas gerando um novo texto. Este novo texto ajudou a produzir um tecido de informações confirmadas que implica mais legitimidade das informações, mais confiança por parte dos entrevistados e mais sentido e autenticidade por parte dos participantes e níveis maiores de elaboração da experiência. Com tais procedimentos, gerou-se, como nos coloca Rey (2005), uma compreensão progressiva do problema estudado, possibilitando uma articulação entre as informações e a teoria em um processo construtivo implícito ao desenvolvimento da pesquisa. 
Acredita Clot (2007) que a reflexão sobre a atividade realizada na presença do outro pode facilitar a discriminação por parte dos sujeitos entre aquilo que fazem, aquilo que dizem que fazem e aquilo que fazem daquilo que dizem, que gesta a possibilidade de desenvolvimento, permitindo-Ihes maior consciência e menos alienação em relação a si mesmo. Para este autor, este movimento de pensar e pôr em palavras as informações fornecidas ao pesquisador, via esta metodologia, permite que estas reflexões sejam transformadas em narrativas, permitindo aos participantes contar suas histórias, replicando com mais acurácia sua experiência vivida.

O que se buscou explicitar através de cada momento da pesquisa foi a produção do sentido da atividade em cada um dos sistemas estudados, para através dela revelar a mediação da emoção na prática docente e sua relevância no processo ensino-aprendizagem.

\section{APRESENTAÇÃO E ANÁLISE DOS DADOS}

Ao expor a presença da emoção nos sistemas de atividades componentes da prática docente, objetivou-se demonstrar sua relevância para um processo significativo de ensino-aprendizagem. Neste sentido foram buscados indicadores empíricos resultantes da autoconfrontação dos professores com os vídeos filmados em sala de aula, durante o desenvolvimento de cada um dos sistemas de atividades propostos da sua prática docente, das entrevistas, das observações e das notas de campo, bem como da triangulação entre elas, sendo apresentados a seguir. A partir destes indicadores empíricos fez-se o confronto com os fundamentos teóricos o que permitiu a legitimação do conhecimento.

Após a análise das falas dos professores e alunos e revisão das notas de campo, emergiram temas recorrentes que foram assim organizados: as comparações entre o curso de administração e os cursos de engenharias da mesma instituição, a preocupação com a formação profissional dos alunos, a imaturidade dos alunos, o uso de aparelhos eletrônicos em sala, os estereótipos e o respeito nas relações. O agrupamento das falas dos sujeitos nesses temas é meramente didático, uma vez que estavam imbricados durante os diálogos.

No entanto, por meio da análise das falas dos professores e alunos sobre estes temas, e dos dados coletados durante uma reunião de professores, em que ocorreram comparações do curso pesquisado com outros cursos ofertados na instituição, foi possível diferenciar os professores que atuavam no curso de Administração em dois grupos. 0 primeiro grupo foi protagonista de comentários depreciativos em relação ao curso pesquisado, os professores deste grupo rotulavam os alunos de administração de imaturos, irrequietos e deficientes em habilidades esperadas para alunos do ensino superior. Os comentários dos professores do segundo grupo divergiram mostrando-se apreciativos, pois consideravam os alunos respeitadores, participativos e hábeis em compreender e questionar os conceitos a eles apresentados. Tal situação revelou que diferentes pressupostos da prática do sujeito podem prejudicar sua interação com os outros, gerar emoções contraditórias e contribuir na construção de sentidos divergentes. A diferença entre os dois grupos de professores é apresentada em relação as suas práticas, construídas e construtoras de diferentes emoções, expressas por professores e alunos. 
O primeiro grupo, formado pelos professores mais antigos na instituição (entre 15 e 20 anos de instituição) buscavam desenvolver nos alunos do curso de administração as mesmas habilidades e comportamentos que creditava aos alunos dos cursos de engenharia, através da metodologia de ensino e da atuação em sala, afirmando que "eu forço eles, vocês têm que fazer exercício, eu cobro o desenvolvimento da habilidade". Como toda a atividade humana possui demandas emocionais específicas (CAMARGO, 2004) e não existe processo cognitivo sem trabalho afetivo, uma vez que a inteligência não pode ser concebida sem afetividade (BRETON, 2009), estes professores declaravam não conseguir "capturar a atenção" dos alunos em prol das atividades que propunham.

O segundo grupo de professores, com no máximo 10 anos na instituição, perceberam as diferenças entre os alunos do curso pesquisado com relação aos demais cursos como uma singularidade de cada um, "a turma tem suas particularidades" e, a partir dessa constatação, buscaram formas diferentes de trabalhar os conteúdos das disciplinas, aproveitando a "energia", o gosto por "interagir" e a disposição dos alunos para o diálogo. 0 número de desistências nas disciplinas ministradas pelo segundo grupo de professores foi menor que nas do primeiro. Quando questionados sobre ligações dos conteúdos das disciplinas com outras disciplinas, com a futura prática profissional e com a vida cotidiana, os alunos conseguiram fazer mais ligações entre os conteúdos das disciplinas do segundo grupo. As emoções suscitadas pelas relações com os professores do segundo grupo apresentaram-se como um chamamento à ação, no caso do primeiro grupo, como uma renúncia a ela (VIGOTSKI, 2010).

Para professores e alunos, o objetivo do curso de Administração é formar profissionais que atuarão na sociedade, inclusive houve professores que expandiram o papel do ensino superior para a "formação da pessoa". Em um primeiro momento, todos os professores pesquisados entenderam o menor número de desistências de alunos nas disciplinas técnicas, ou profissionalizantes, como uma demonstração de preferência dos alunos por tais disciplinas, pela maior facilidade em relacioná-las à futura atuação profissional.

Os alunos conseguiram fazer mais ligações de disciplinas técnicas com outras disciplinas do curso e com a futura prática profissional, mas avaliaram como muito extenso o período de três aulas seguidas em uma mesma disciplina. No entanto, houve uma disciplina, ministrada por um professor do primeiro grupo, que mesmo sendo técnica, teve seu aproveitamento reduzido em função da didática do professor e pelo relacionamento deste com os alunos em sala, levando-os a declarar que, por "odiarem" o tratamento a eles dispensado, passaram a odiar a disciplina. Confirmando que somente os aspectos formais e visíveis como conteúdo programático não mobilizam os alunos, são as emoções decorrentes da implicação pessoal que conferem significado aos acontecimentos (BRETON, 2009).

Também contrariando a expectativa de preferência dos alunos pelas disciplinas técnicas, a disciplina apontada como a melhor do semestre foi uma disciplina de formação básica, essencialmente teórica e não técnica, ministrada por um professor do segundo grupo, que em função da dinâmica conferida pelo professor e pelo relacionamento estabelecido em sala, foi considerada pelos alunos uma disciplina "mais leve", apesar da carga horária de três aulas seguidas. Os alunos creditaram tal avaliação à abertura dada para participação dos alunos, de não ocorrem repreensões, de serem realizadas atividades em grupo e pela integração de temas contemporâneos e assuntos cotidianos ao conteúdo das aulas. 
Ainda que os professores das disciplinas de cálculos tenham buscado usar termos do linguajar da administração, como preço, custo, demanda, entre outros, e tenham objetivado educar os alunos para a futura atuação profissional, ocorreram confrontos em sala de aula e a necessidade de repetições na tentativa de despertar o interesse dos alunos para o que estava sendo ministrado. Não surpreendeu estes professores as desistências e reprovações. Como constatou Goleman (1995), quando a emoção subtrai a concentração, o que está sendo subtraído de fato é a capacidade mental cognitiva ou memória funcional, isto é, a capacidade de ter em mente toda a informação relevante para a execução de uma determinada tarefa, como resolução de exercícios ou provas.

Ao final de uma aula de cálculo os alunos não conseguiram fazer ligações com outras disciplinas do curso, tampouco com a futura atuação profissional e não compreendiam o porque da grande carga horária de tais disciplinas. Alerta Clot (2010) que a divergência do sentido atribuído pelos sujeitos à uma atividade pode ocasionar o esvaziamento do sentido da atividade, que impelirá os sujeitos a dispersar em busca de outra atividade que Ihes faça sentido.

O professor de uma disciplina de cálculo, atuante na instituição há vinte anos, desabafou sua frustração com as turmas do curso de administração, pois não compreende 0 desinteresse e descaso dos alunos frente à oportunidade de estar cursando ensino superior em uma instituição pública federal. Para ele, os jovens na faixa etária dos dezesseis a vinte e poucos anos, demonstram não ter ambições e ser conformados às condições socioeconômicas que a família e a sociedade lhes oferecem. A postura de severidade durante a aula, enquanto expressão emocional, creditada a seu modo de ser habitual, estabeleceu e manteve uma posição de distanciamento em relação aos alunos, que buscavam auxílio entre si para resolver os exercícios propostos e não junto ao professor, ao que ele interpretou como consequência de "medo". Apesar da importância da interação com colegas que detenham maior conhecimento para realização de uma tarefa (VIGOTSKY, 1998), esta não suprime a necessidade de uma parceria significativa com o professor para elaboração de novos conhecimentos (GARNIER; BEDNARZ; ULANOVSKAYA, 1996).

$\mathrm{Na}$ análise das expressões emocionais das falas dos alunos, estas se mostraram ligadas às interpretações feitas pelos indivíduos com relação a acontecimentos que os afetaram moralmente e modificaram ao longo de dois semestres a relação com o curso (BRETON, 2009). Emoções derivadas da maneira como a percepção trabalha na mente humana, em conjunto com outras mentes humanas (BARRETT, 2012) e, embora não claramente perceptíveis, eficazes na sua interferência na consciência dos sujeitos (LANE, 1999), levaram os alunos a relatar um sentimento de não pertencimento à instituição de ensino. Esse sentimento se opôs à declaração da maioria dos alunos de que a instituição foi diferencial na escolha do curso e que pretendem concluí-lo, mesmo este não tendo sido sua primeira opção de ensino superior.

Uma vez que a emoção não existe desvinculada da formação da sensibilidade que o relacionamento com os outros enseja no seio de uma cultura e em um contexto particular, essa contradição demonstrou que emoções como desafeto, antipatia, ressentimento, não aceitação e depreciação permeavam as relações dos alunos com professores e a instituição. Os alunos denunciaram certa preferência dos professores pelos que tinham melhor desempenho, mesmo sem terem ouvido tal afirmação. Como alerta Camargo (2004), a emoção, 
que tem como sua primeira função a comunicação, informa posicionamentos dos sujeitos frente à realidade, mesmo sem palavras. Para os alunos há um clima de competição e individualismo entre os próprios colegas de turma em função da valorização de desempenho em sala.

A constante presença de notebooks e celulares em sala de aula para o primeiro grupo de professores foi motivo de diversas solicitações para que fossem desligados e guardados, ao que os alunos, mesmo que demonstrando desgosto, atendiam momentaneamente voltando a utilizá-los em seguida, em uma clara atitude de confronto.

Quanto ao segundo grupo, o uso dos aparelhos eletrônicos foi tido como uma demanda da atualidade em que a dinamicidade e capacidade para fazer várias coisas ao mesmo tempo são prementes. Em uma demonstração de remodelação de sua prática, em função do relacionamento com o mundo (BRETON, 2009; BULGACOV; VIZEU, 2011), um dos professores mostrou-se disposto a "dar um espaço para que os alunos administrem e mostrem a sua maturidade" gerindo eles próprios o uso de seus aparelhos eletrônicos. Depositários de tal confiança, os alunos, mesmo com notebooks ligados e celulares sobre as carteiras, mostraram-se participativos durante a aula, fazendo comentários e questionamentos, demonstrando que, uma vez estabelecido o vínculo emocional que os implicou na atividade, qual fosse a atividade pautada nos aparelhos eletrônicos esta perdeu importância, tornando-se uma atividade-meio e não mais uma atividade-fim (HELLER, 1993).

Em relação ao excesso de conversas paralelas, as causas apontadas e tratamentos dispensados foram diferentes, distinguindo-se novamente os dois grupos de professores anteriormente citados. O primeiro, para fazer frente às conversas paralelas imprimiu um ritmo acelerado de aula, tom de voz mais alto, grande movimentação dentro da sala e extenso rol de atividades. 0 segundo grupo questionou a própria responsabilidade no comportamento adotado pelos alunos, e mesmo tendo que solicitar silêncio várias vezes, não se sentiram afrontados ou desrespeitados. Atentaram para o retorno dado pelos alunos, de que conversavam para não dormir em sala, e admitiram a necessidade de mudar a dinâmica das aulas para amenizar as conversas paralelas. Diminuíram o tempo das aulas expositivas e o intercalaram com outras atividades como trabalho em grupo e debates, "uma aula expositiva de três aulas seguidas, tanto pra mim quanto pra eles seria cansativo", demonstrando aprendizado social e identificação com os outros. Essas duas dimensões da emoção alimentam conjuntamente a sociabilidade (BRETON, 2009).

A "turma do fundão" também foi pauta das falas dos professores, seguindo com os dois diferentes posicionamentos anteriores. O primeiro grupo avaliou que com um semestre de aula foi possível identificar a qual "turma" os alunos pertenciam, para realizar mudanças dentro da sala de aula com o objetivo de extinguir os grupos informais, os quais, no seu parecer, prejudicam o bom andamento da aula. Porque o "pessoalzinho" que senta no fundo da sala é mais "folgado" e conversa mais, fazê-los sentar nas primeiras carteiras foi uma das estratégias.

O segundo grupo de professores relatou experiências com trabalhos nos quais os alunos da "turma do fundão" surpreenderam "porque foram os mais criativos", para eles os alunos "do fundão" têm uma capacidade que está sendo subaproveitada. Estes professores também se posicionaram contrários à imposição de troca de lugares em sala de aula, considerando tal atitude como constrangedora. 
Os alunos confessaram que "odiavam" ser rotulados, principalmente porque percebiam tratamento diferenciado, considerado por eles "injusto", em relação aos demais alunos da turma, lembramos que Camargo (2004) relaciona emoções mais negativas com maiores dificuldades na escola e evasão.

Todos os professores manifestaram dispensar respeito aos alunos, mas em suas falas "respeito" demonstrou ter diferentes sentidos. Para alguns um tratamento respeitoso significava distanciamento e pequenas concessões como o direito de escolha de exercícios a serem resolvidos em sala de aula. Para outros, representava um tratamento igualitário, de confiança e acessibilidade, tratar os alunos como gostariam de ser tratados. Para os alunos esses diferentes sentidos resultaram em tratamentos muito diferentes. Pela perspectiva deles, houve professores que deram muitas broncas e que os tratavam como crianças, outros, no entanto, os tratavam como adultos, eram acessíveis e os ouviam, considerando relevantes suas observações e partindo do pressuposto que eles, em relação às tarefas, fariam mais do que o solicitado. Esses diferentes tratamentos geraram diferentes relações e reações.

As falas dos alunos, quanto às disciplinas ministradas pelos professores do primeiro grupo, expressaram mais dificuldade em estabelecer relações entre os conteúdos ministrados e outras disciplinas, a futura atuação profissional e a vida cotidiana, mesmo concordando que as disciplinas haviam cumprido o conteúdo programático. Dentre as imagens evocadas ao final das aulas estavam muitos pontos de interrogação e "cabeças emitindo fumaça". Em relação às disciplinas ministradas pelos professores do segundo grupo, os alunos conseguiram estabelecer relações com outras disciplinas, com a futura atuação profissional e com a vida cotidiana. Os objetivos excederam o cumprimento das ementas, alcançando amadurecimento e capacidade de reflexão. Corroborando que a emoção é a responsável pela seleção das percepções que estão armazenadas na memória de curto prazo e que passarão para a memória de longo prazo, rejeitando as percepções em que o sujeito não está implicado (HELLER, 1993).

As imagens evocadas pelas disciplinas do segundo grupo de professores foram mais nítidas e concretas, como a de uma empilhadeira, de estátuas e de gráficos. Aulas que os capturaram e os levaram além de experiências anteriores, a saírem de si e a entrarem em outros devires (KASTRUP 1999). Isso ocorreu através de uma relação de aceitação, em que os alunos não temiam manifestar-se em sala, e por um tratamento de igualdade baseado em responsabilidade, "a gente gostava do jeito como tratava a gente, como adultos". Para Galvão (2003) foi a aproximação da emoção, sua propagação epidérmica, que provocou esse estado de comunhão e de uníssono, que diluiu as fronteiras entre os sujeitos, levando os esforços e intenções a voltarem-se para um objetivo comum. Reforçando também que a mediação de emoções como afeto, simpatia, amizade e aceitação, constrói sentidos compartilhados.

Lembrando que emoções comunicam e criam vínculos de afiliação, as emoções expressas pelos professores foram notadas pelos alunos, que relataram perceber nos professores mais ou menos disposição, ânimo, vontade e interesse ao ministrar suas aulas e mais ou menos acessibilidade aos alunos, além da diferença nas emoções que suscitavam.

Ao se confrontarem as diferenças da prática entre professores, com as emoções expressas pelos alunos, o que se observou foi que a prática dos professores do primeiro grupo suscitou "ressentimento, raiva, sentimento de injustiça, tristeza, depreciação, vergonha, de- 
safeto, antipatia e medo", emoções que construíram sentidos divergentes entre professores e alunos. Mesmo que a atividade tivesse iniciado com base em um sentido compartilhado e tido como legítimo, novos sentidos se introduziram na atividade em função das emoções que emergiram e se mostraram contrárias à sustentação das atividades propostas e impeditivas da geração de novas atividades em que os alunos se implicassem (VIGOTSKI, 2010).

Em relação às práticas do segundo grupo de professores sobressaiu-se "o prazer de estar em sala, afeto, simpatia, amizade, alegria e aceitação", que contribuíram na construção de sentidos compartilhados por professores e alunos, sustentando as atividades propostas e gerando novas atividades de cooperação sistemática (VIGOTSKI, 2010).

Para Garnier, Bednarz e Ulanovskaya (1996), a prática docente, enquanto sistemas de atividade pode modificar tanto o aluno quanto o professor, desde que este se disponha a refletir, a repensar sua prática. Lembrando que para Clot (2007), o movimento/ ato de pensar já é a história de um desenvolvimento, por isso é importante ressaltar que, após a realização da pesquisa, todos os professores relataram a intenção de rever sua prática docente, considerando isso como positivo e necessário, também pretendiam continuar ministrando aulas no curso.

Os encontros entre pesquisador e pesquisados demonstraram a importância do tempo de interação com os sujeitos da pesquisa, necessário para que um método dialógico, como o proposto, possa concretizar a possibilidade de uma alteração qualitativa nos processos de pensamento dos sujeitos (VIGOTSKI, 2010). A pesquisa propiciou momentos de reflexão sobre a prática docente para todos os envolvidos, corroborando a complexidade e não compartimentalização do sujeito concreto (BULGACOV; VIZEU, 2011).

\section{CONSIDERAÇÕES FINAIS}

Recuperando-se abordagens que consideram a prática social como meio de confrontar concepções abstratas na teoria das organizações, esta pesquisa tomou como unidade de análise a prática docente teorizando-a a partir da Teoria da Atividade proveniente da Psicologia Histórico-cultural fundada em uma concepção histórica de realidade concreta e uma concepção de homem constituído e constituinte da cultura. Uma concepção de homem que entende que é a emoção que dinamiza e torna significativa a atividade. Face a este contexto, objetivou-se demonstrar a presença da emoção na prática docente, bem como seu papel dinamogênico e sua relevância em um processo significativo de ensino-aprendizagem.

As coletas, bem como a análise dos dados, foram orientadas por uma epistemologia construtivo-interpretativista, vinculando a interpretação ao contexto como apregoa Clot (2007). Foram apontados indicadores empíricos, que confrontados com a teoria, geraram zonas de inteligibilidade sobre a emoção e seu papel na significação do processo de ensino-aprendizagem, garantindo-se assim a legitimidade do conhecimento produzido. Assim, considera-se que o objetivo de apresentar a emoção na prática docente no ensino de Administração a partir de uma análise situada foi alcançado.

A partir dos resultados expostos ratifica-se, em primeiro lugar, que a emoção está presente em toda atividade humana, sendo gênese e sustentação desta atividade. Segundo, que diferentes práticas suscitam diferentes emoções, sendo que a mediação da emoção 
pode ser a mola propulsora de um processo significativo de ensino-aprendizagem, pois é através dela que o sujeito constrói sentido. No curso pesquisado diferenciaram-se duas práticas docentes, uma que evocou emoções contraditórias e contribuiu na construção de sentidos divergentes, causando impedimento e esvaziamento das atividades e outra prática que, ao evocar emoções harmônicas contribuíam na construção de sentidos compartilhados por professores e alunos, sustentando as atividades propostas e gerando novas atividades de cooperação sistemática (VIGOTSKI, 2010).

A limitação da pesquisa foi a necessidade de encerrar a mesma antes de ocorrerem as mudanças prenunciadas pelos professores, que possibilitaria verificar alterações qualitativas no pensamento e na prática docente dos sujeitos (VIGOTSKI, 2010).

Espera-se que a presente pesquisa contribua para reflexão dos docentes, na construção de uma educação mais significativa e, por conseguinte, mais sensível e efetiva, para os alunos, professores e sociedade. A zona de inteligibilidade gerada a partir desta pesquisa não esgota a questão da mediação da emoção na prática, sugere-se seu aprofundamento sobretudo destacando o potencial da abordagem sócio-histórica para contribuir na construção de teorias que têm como foco as práticas cotidianas da organização e uma concepção de homem concreto

\section{REFERÊNCIAS}

BARRETT, L. F. Emotions Are Real. Emotion, v. 12, n. 3, 2012. p. 413-429.

BRETON, D. L. As paixões ordinárias: antropologia das emoções. Petrópolis: Vozes, 2009.

BULGACOV, Y. L. M.; VIZEU, F. A positividade da emoção na prática da pesquisa social em organizações. Cadernos EBAPE, v. 9, n. esp. 1, p. 488-509, jul. 2011.

CAMARGO, D. As emoções \& a escola. Curitiba: Travessa dos Editores, 2004.

CAMARGO, D.; BULGACOV, Y. L. M. Identidade e emoção. Curitiba: Travessa dos editores, 2006.

CAMARGO, D. Notas de discussão para grupo de estudo. Grupo de Pesquisa - Práticas, Subjetividade e Organizações, Curitiba, 2012.

CANOPF, L. Análise situada da prática docente no ensino de administração: revelando a mediação da emoção no curso da UTFPR - Campus Curitiba. 2013. 158f. Tese (Doutorado em Administração). Universidade Positivo, Curitiba.

CASSANDRE, M. P. et al. Gênero e Estilo na prática das Manipuladoras de Alimentos: uma aproximação empírica aos estudos organizacionais na perspectiva sócio-histórica e cultural. In: ANPAD. Anais... Rio de Janeiro, 2010.

CHANLAT, J.-F. Por uma antropologia da condição humana nas organizações. In: CHANLAT, J.-F. (org.). $\mathbf{O}$ indivíduo na organização: dimensões esquecidas. Tradução de Arakcy Martins Rodrigues. v. 1. São Paulo: Atlas, 1996.

CLOT, Y. A função psicológica do trabalho. Tradução de Adail Sobral. Petrópolis: Vozes, 2007. 
CLOT, Y. Trabalho e poder de agir. Tradução de Guilherme João Freitas Teixeira e Marlene Machado Zica Vianna. Belo Horizonte: Fabrefactum, 2010.

DANIELS, H. Vygotsky e a pesquisa. Tradução de Milton Camargo Mota. São Paulo: Edições Loyola, 2011.

DAVEL, E. et al. Revitalizando a relação ensino-aprendizagem em administração por meio de recursos estéticos. In: ANPAD. Anais.... Curitiba, 2004.

ENGESTRÖM, Y. Learning by expanding: an activity-theoretical approach to developmental research. Helsinki: Orienta-Konsultit, 1987.

GALVÃO, I. Expressividade e emoções Segundo a Perspectiva de Wallon. In: ARANTES, V. A. (org.). Afetividade na escola: alternativas teóricas e práticas. São Paulo: Summus, 2003.

GARNIER, C.; BEDNARZ, N.; ULANOVSKAYA, I. Após Vygotsky e Piaget: perspectivas social e construtivista. Escolas russa e ocidental. Tradução de Eunice Gruman. Porto Alegre: Artes Médicas, 1996.

GOLEMAN, D. Inteligência Emocional. Tradução de Marcos Santarrita. Rio de Janeiro: Objetiva, 1995.

HELLER, A. Teoria de los Sentimentos. México: Distribuciones Fontamara S.A., 1993.

INEP - Instituto Nacional de Estudos e Pesquisas Educacionais Anísio Teixeira. Matrículas no ensino superior crescem 3,8\%. Censo da educação superior, 9 de setembro de 2014. Disponível em: <http://portal.inep.gov.br/visualizar/-/asset_publisher/6AhJ/content/matriculas-no-ensino-superior-crescem-3-8> . Acesso: 29 de dez. 2016.

KASTRUP, V. A invenção de si e do mundo: uma introdução do tempo e do coletivo no estudo da cognição. Campinas: Papirus, 1999.

LANE, S. T. M. Os fundamentos teóricos. In: LANE, S. T. M.; ARAÚJO, Y. (org.). Arqueologia das emoções. Petrópolis: Vozes, 1999.

LEONTIEV, A. 0 desenvolvimento do psiquismo. Tradução de Rubens Eduardo Frias. São Paulo: Centauro, 2004.

LIBÂNEO, J. C. A didática e a aprendizagem do pensar e do aprender: a Teoria Histórico-cultural da Atividade e a contribuição de Vasili Davydov. Revista Brasileira de Educação. 27, set.-dez., p. 5-24, 2004.

LOURENÇO, C. D. da S. et al. A reconciliação entre o econômico e o social: um desafio para o ensino de administração. In: ANPAD. Anais.... Curitiba, 2009.

MAFFESOLI, M. Elogio da razão sensível. Tradução de Albert Stuckenbruck. Petrópolis: Vozes, 2005.

GUERREIRO RAMOS, A. A Nova ciência das organizações: uma reconceituação da riqueza das nações. Rio de Janeiro: Fundação Getúlio Vargas, 1981.

REY, F. L. G. Sujeito e Subjetividade: uma aproximação histórico-cultural. São Paulo: Pioneira Thomson Learning, 2003.

Pesquisa Qualitativa e Subjetividade: os processos da construção da informação.

São Paulo: Pioneira Thomson Learning, 2005. 
ROMANELLI, N. A questão metodológica na produção vigotskiana e a dialética marxista. Revista Psicologia em Estudo, Maringá, v. 16, n. 2, p. 199-208, abr./jun. 2011.

SFORNI, M. S. F. Aprendizagem de conceitos científicos e desenvolvimento do pensamento teórico. In: I Congresso Internacional de Psicologia e V Semana de Psicologia da UEM. Maringá: UEM, 2003. p. 1-12.

TEIXEIRA, E. Vigotski e o materialismo dialético: uma introdução aos fundamentos filosóficos da Psicologia Histórico-Cultural. Pato Branco: FADEP, 2005.

VALADÃO, J. A. D. Que é Fazer Científico em Administração? In: ADM2011, UEPG. Anais... Ponta Grossa, 2011.

VIGOTSKY, L. S. A formação social da mente: o desenvolvimento dos processos psicológicos superiores. Tradução de Jéferson Luis Camargo. 6. ed. São Paulo: Martins Fontes, 1998.

Psicologia Pedagógica. Tradução de Paulo Bezerra. 3. ed. São Paulo: WMF Martins Fontes, 2010.

Data de submissão: 17/06/2016.

Data de aprovação: 19/07/2017. 